\title{
Erratum: Acute and sub-acute toxicity of the crude extracts of the aerial parts of Daucus carota L. in laboratory rats
}

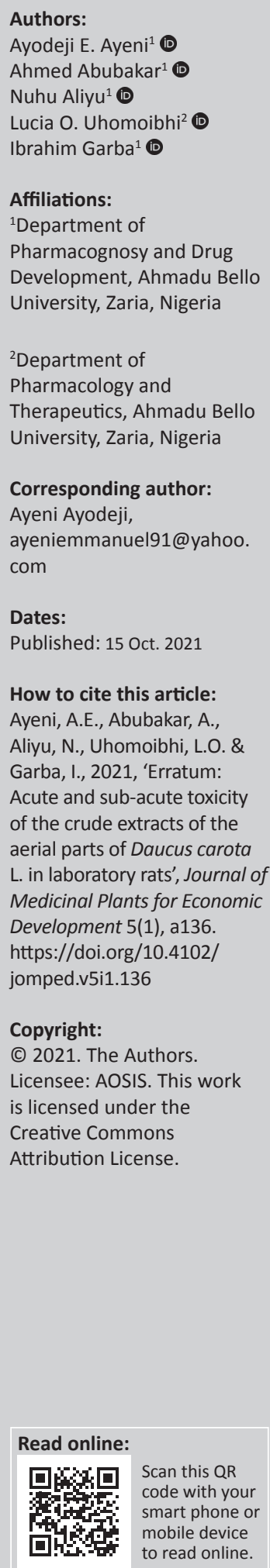

In the version of the article initially published, Ayeni, A.E., Abubakar, A., Aliyu, N., Uhomoibhi, L.O. \& Garba, I., 2019, 'Acute and sub-acute toxicity of the crude extracts of the aerial parts of Daucus carota L. in laboratory rats', Journal of Medicinal Plants for Economic Development 3(1), a69. https://doi.org/10.4102/jomped.v3i1.69, some of the $p$-values in the 'Results' section was incorrectly displayed as $p$-. The values should have reflected as $p \leq$.

The 'Results' section is hereby updated to:

\section{Results}

\section{Acute toxicity}

The acute oral toxicity of graded doses of the n-hexane, ethyl acetate and methanol extracts of D. carota aerial part was administered, respectively. The animals were observed for 14 days, and no mortality or any toxic signs such as tiredness, weakness, convulsion, hyperactiveness, dullness, diarrhoea and diuresis were noticed in the extracts, respectively, even at a high dose of $5000 \mathrm{mg} / \mathrm{kg}$.

\section{Sub-chronic toxicity}

\section{Body weight}

During the second week, there was significant $(p \leq 0.05)$ weight loss in the HAEDC and MAEDC with 500, 1000 and $1500 \mathrm{mg} / \mathrm{kg}$ lost when compared with a control group and there was no significant difference $(p \geq 0.05)$ in the EAEDCtreated group (Table 1).

\section{Haematological parameters}

The effects of the daily oral administration of the HAEDC, EAEDC and MAEDC showed a statistically significant decrease $(p \leq 0.05)$ on the red RBC at different doses when compared with the control group. However, there was a significant $(p \leq 0.05)$ increase in the MCV of HAEDC and EAEDC with doses of $1000 \mathrm{mg} / \mathrm{kg}$ and $1500 \mathrm{mg} / \mathrm{kg}$ when compared with the control group. Furthermore, EAEDC at a dose of $500 \mathrm{mg} / \mathrm{kg}$ showed a significant $(p \leq 0.05)$ increase in the $\mathrm{MCH}$ when compared with the control group (Table 2).

\section{Biochemical parameters}

There was no significant difference between the serum liver biomarker, AST, alanine amino transferase (ALT), TP and ALB in the treated group and control group. However, there was a significant $(p \leq 0.05)$ decrease in ALP of all the treated groups when compared with control group (Table 3).

There was no significant change in the serum kidney biomarkers (urea, sodium, potassium, creatinine and chloride) in the treated group when compared with the control group. However, there was a significant $(p \leq 0.05)$ decrease in the serum bicarbonate level in HAEDC with $500 \mathrm{mg} / \mathrm{kg}, 1000 \mathrm{mg} / \mathrm{kg}$ and $1500 \mathrm{mg} / \mathrm{kg}$ and MAEDC with $1000 \mathrm{mg} / \mathrm{kg}$ and $1500 \mathrm{mg} / \mathrm{kg}$ body weight when compared with the control group (Table 4).

The publisher apologises for any inconvenience caused. 